Dolores Aponte-Ramos y Elisa Rizo, Guinea Ecuatorial como pregunta abierta: hacia el diálogo entre nuestras otredades

\title{
I. Propuestas locales ante el forum indePendentista del África OCCIDENTAL
}

Dorothy Odartey-Wellington, "Ecuatorial Guinea Is Different": literatura colonial de Guinea Española en África Occidental ............. .

Rosario M. De Swanson, Autoetnografía, espacio, identidad y resistencia en la narrativa fundacional de Guinea Ecuatorial: Cuando los combes luchaban (1953) de Leoncio Evita Enoy ... ............................ .

M'bare N'Gom, Dislocación, memoria histórica e identidad en "La travesía" de Francisco Abeso

\section{JuEgOS TRANSATLÁNTICOS: TIERRA, LÍRICA Y CANTO}

Dosinda García-Alvite, Paisajes del exilio en la poesía de Juan Balboa Boneke: compromiso social con la patria guineoecuatoriana ........... Cristina Rodríguez Cabral, Musas de ébano: marcha a través del

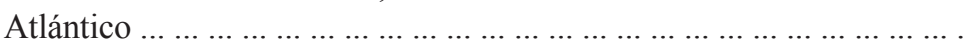

Nayra Pérez Hernández, Lenguaje, espacio y exilio en la poesía

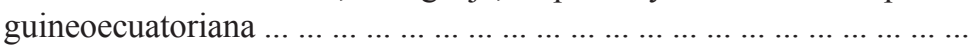


III. El ESPAÑOL EN ÁFricA Y MÁS ALLÁ: LAS OTRAS HISTORIAS LITERARIAS Y LOS OTROS MAPAS LINGÜÍSTICOS

JoHN M. LiPSKi, ¿Existe un dialecto “ecuatoguineano” del español? ... ...... 865 JosEPH-DÉSIRÉ OTABELA, Resistencia política y creación literaria en Guinea Ecuatorial

Alain Lawo-SuKam, Hispanismo en África Subsahariana más allá de la colonia: una aproximación a la literatura hispano-camerunesa ... ........

\section{Sobre el teatro en Guinea Ecuatorial, con saludos a AmÉRICA LATINA}

Elisa Rizo, El teatro de Guinea Ecuatorial: intrahistoria en tres actos

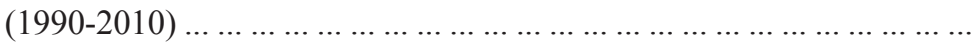

María Zalduondo, La africanización de Antígona (Guinea Ecuatorial, 1991) por Trinidad Morgades Besari y su horizonte de expectativas: una comparación con Antígona, furiosa (Argentina, 1988) de Griselda

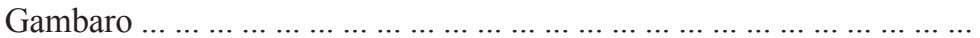

\section{Pliegos, porosidades: Reubicación de fronteras, CÁnones E HISTORIOGRAFÍAS}

Michael Ugarte, Cortes fronterizos: convergencias entre Las tinieblas de tu memoria negra de Donato Ndongo y Une vie de boy de Ferdinand

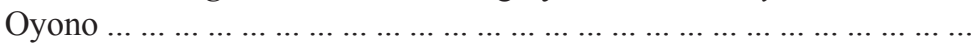

CRistián H. Ricci, El discurso paródico afro-occidental de los escritores

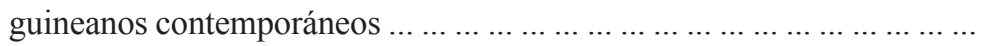

Selena Nobile, G2 y la reterritorialización en una matria migrante: Igiaba Scego y Guillermina Mekuy ................................... .

Nicole D. Price, La deconstrucción del discurso hegemónico a través del cuerpo y medioambiente en La carga de Juan Tomás Ávila Laurel ... ...

Clément Akassi Animan, De la literatura ecuatoguineana en cuestión, bajo "L'Arbre à palabres" 


\section{LECTURAS Y LECTORES DE TEXTOS SILENCIADOS}

Olga Arbeláez, Geografías imposibles: hogar y nación en las novelas de

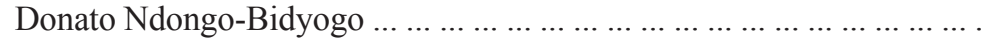

Clelia Rodríguez, A Nnanga, mi amiga vieja. Lástima que no sepa leer ... JuAN De URDA, La obra de Francisco Zamora y su lector implícito ......... Dolores Aponte Ramos, Leer en el umbral: apuntes sobre la función del lector en la literatura guineo-ecuatoriana $\ldots \ldots \ldots \ldots \ldots \ldots \ldots \ldots \ldots \ldots$

\section{LA NACIÓN ROTA: VISIONES DESDE EL INSILIO}

Justo Bolekia Boleká, Guinea Ecuatorial: descolonizando nuestro

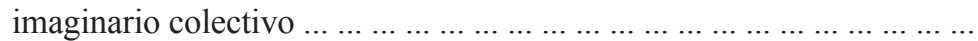

José Fernando Siale Duangany, Procesando la modernidad: anatomía de

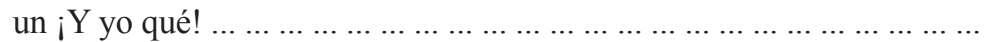

JuAn TOMÁs Ávila LAUREL, Letras guineanas, pasos necesarios ............ .

Recaredo Silebo Boturu, El desafío de un Dézafi: el teatro como arte y arma letal, una particular lectura-postura de Dézafi ... .................

\section{ENTREVISTAS}

EuIsa Rizo, Entrevista a Guillermina Mekuy Mba Obono ... ... . . . . . . . . . ... 1133

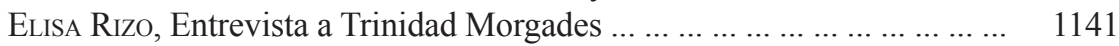

\section{RESEÑAS}

Thenesoya Vidina Martín de la Nuez sobre Marvin Lewis, An Introduction to the Literature of Equatorial Guinea. Between Colonialism and

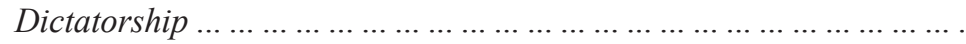


